ORIGINAL ARTICLE

\title{
Non-fatal firearm injuries, Incidence and Circumstances: Presenting in DHQ Hospital Rawalpindi
}

\author{
TASNEEM MURAD ${ }^{1}$, SHEEBA SHABIR ${ }^{2}$, KHURRAM SALEEM ${ }^{3}$, YASIR SHEHZAD ${ }^{4}$, NOOR UL AIN ${ }^{5}$, SADAF ZAHRA $^{6}$ \\ ${ }^{1}$ Assistant Professor, Forensic Medicine and Toxicology Department Islamic International Medical Collage, Rawalpindi \\ ${ }^{2}$ Assistant Professor Forensic Medicine Department Hazrat Bari Sarkar Medical and Dental Collage, Rawalpindi \\ ${ }^{3}$ Demonstrator Forensic Medicine, Sheikh Zayed Hospital, Rahim Yar Khan \\ ${ }^{4}$ Assistant Professor of Neurosurgery Rawalpindi Medical University, Rawalpindi \\ ${ }^{5}$ DemonstratorForensic Medicine department Islamic International Medical Collage Rawalpindi \\ ${ }_{6}^{6}$ MBBS Demonstrator Forensic Medicine department Islamic International Medical collage Rawalpindi \\ Corresponding Author: Dr. Tasneem Murad, Email: tasneem.murad@riphah.edu.pk, Contact no.+923005319963
}

\begin{abstract}
Objective: To describe the incidence and manner of nonfatal firearm injuries in Rawalpindi District Study design: Observational retrospective study

Place and Duration: District Head Quarters Hospital Rawalpindi. Duration of 6 months, from July 2020 to Dec 2020.

Methodology: Total 82 patients with nonfatal firearm injuries were included. After approval from ERC committee of DHQ Hospital Rawalpindi, data was obtained from the duplicate copies of medicoleagal reports kept at the Forensic Medicine department $t$ of IIMCT. These reports were carried out by cross ponding author and the demonstrators of Forensic Medicine department of IIMCT. The data was entered on a pre-designed Performa having variables such as demographics, time \& place of death, region of body involved, weapon used \& month of the year.

Results: A total of 82 nonfatal firearm injuries were reported during these 6 months. $87 \%$ of the victims of were males encountering injuries 1 to 11 in number with an average of 3 injuries per person. $30 \%$ of these injuries were received on the upper trunk, 32\% on the lower trunk, $16 \%$ the lower limbs, $13 \%$ the upper limb, $3 \%$ the head and neck and $6 \%$ on the other regions. $68 \%$ of the injuries were lacerations, an exit wound was detected in $19 \%$ of cases and in $13 \%$ only entry wounds were found. Tattooing and burning of the adjacent skin were common in wounds on the upper and lower trunk while comminuted intra articular and shaft fractures were important varieties in the limbs. $86 \%$ of the victims were vitally stable, others being critically unstable with GCS ranging till 6/15.

Conclusion: The public health issue of firearm-related injuries continues to be a concern. The necessity for a district-based, nationwide reporting system for fatal and nonfatal firearm-related injuries is critical. In Pakistan, these data could be used in the design, implementation, and assessment of preventative programs.

Key words: Non fatal, Firearm injuries, Regional injuries
\end{abstract}

\section{INTRODUCTION}

Allah likes contended \& obliged human. But in today's environment, we are so far far from this value that it is depressing (1). The current COVID 19 pandemic and our financial and social stress levels have led to continuous negative thoughts that have led to behavioral changes. Due to these changes, the ability to distinguish right from wrong and legal from criminal has been compromised (2). Unfortunately, this is one of the factors contributing to an increase in homicides in rich (3) as well as emerging countries around the world (4)

In 2017, Pakistani individuals voluntarily submitted more than 89,000 illicit guns for destruction. Recent amnesty and collecting programs have led to the destruction of 641,107 weapons. Pakistan's National Report for 2018 outlines the government's initiatives, published on June 1, 2018. (5)

As a whole, the rate of violence-related deaths in lowto-mid-income nations was more than double that of countries with higher incomes, but rates vary between regions and provinces within countries(6). $80 \%$ of Baluchistan and KPK's population owns firearms for this purpose, according to a survey by Pakistan's Bureau of Statistics (7)(8). In Punjab and Sindh, the situation is similar (9)
Historically, guns have been used for both homicidal and suicide purposes(10), providing a quick and easy way to injure or kill someone. In most regions of the world, firearm weapons of various varieties are widely available to the public. As a result, they are included in the unregulated pool of lethal weapons that can only be eradicated by governments adopting rigorous gun control regulations and by the public's cooperation(11) (10). Gun possession and firearm-related morbidity and mortality rates have declined dramatically as a result of law enforcement authorities implementing policies properly (12)

Enmity, community confrontations, family disputes or suicide are the leading causes of firearm-related injuries in the United States. There is substantial tissue necrosis in high velocity rifle and shotgun wounds.(13) In high velocity rifle and shotgun wounds, the damage to soft tissues and bone is tremendous. Cavitational effects are frequently absent in low velocity pistol or handgun injuries, on the other hand.(7) (14)

Patients at Rawlpindi's DHQ hospital suffered firearmrelated injuries. Our study sought to determine the circumstances, risk categories, extent, and severity of these injuries in Rawlpindi patients. 


\section{MATERIAL AND METHODS}

It is a descriptive, observational, retrospective study conducted over a period of 06 months i.e. from July to Dec 2020.

After approval from ERC committee of DHQ Hospital Rawalpindi, data was obtained from the duplicate copies of medicoleagal reports kept at the Forensic Medicine department $t$ of IIMCT. These reports were carried out by cross ponding author and the demonstrators of Forensic Medicine department of IIMCT. Homicidal injuries by other means besides firearm were excluded.

The data was entered on a pre-designed Performa having variables such as demographics, time \& place of death, region of body involved, weapon used \& month of the year.

We categorized our variables in numeric form. Then the data was entered, organized, tabulated \& analyzed in SPSS version 20.

\section{RESULTS}

A total of 82 nonfatal firearm injuries were reported during these 6 months. $87 \%$ of the victims of were males encountering injuries 1 to 11 in number with an average of 3 injuries per person.(15) $30 \%$ of these injuries were received on the upper trunk, $32 \%$ on the lower trunk, $16 \%$ the lower limbs, 13\% the upper limb, 3\% the head and neck and $6 \%$ on the other regions( Figure 1). $68 \%$ of the injuries were lacerations, an exit wound was detected in $19 \%$ of cases and in 13\% only entry wounds were found (Figure 2). Tattooing and burning of the adjacent skin were common in wounds on the upper and lower trunk while comminuted intra articular and shaft fractures were important varieties in the limbs(16). $86 \%$ of the victims were vitally stable, others being critically unstable with GCS ranging till 6/15.

There was no any association of occupation found inrisk of firearm injuries, in which most of the victims were engaged in simple occupations such as labour, farming, taxi driving and most of the incidence associated with property dispute and robbery.

Figure 1: Percentages of wounds on various Regions of the body

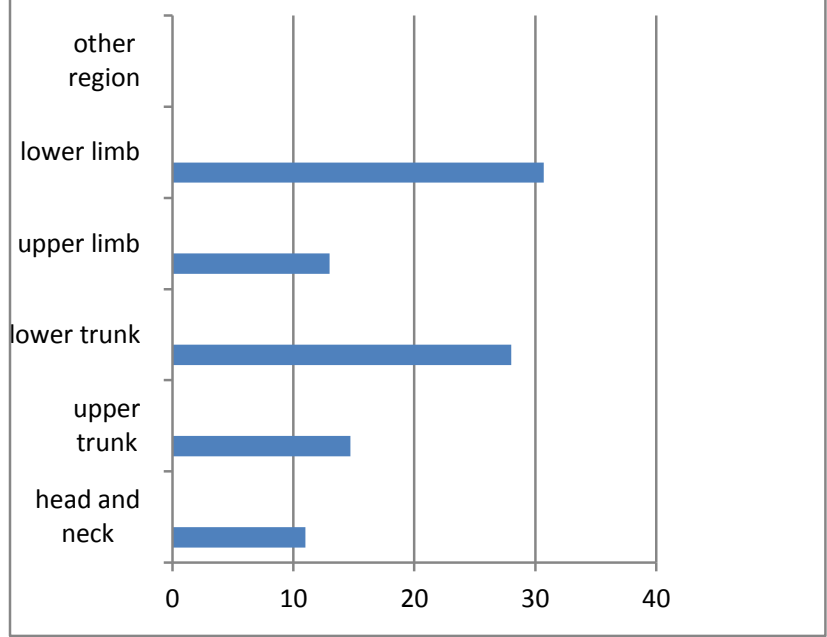

Figure 2

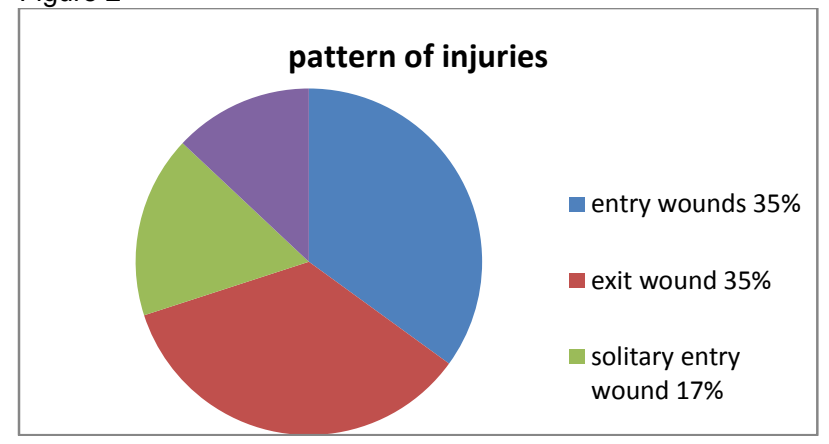

The figure 3 depicts that the total no of cases in the six months. The maximum no of cases were reported in July and December 2020.15 cases were reported in the month of August 2020.Mostly cases were reported from Dhok Banaras, Dhok Dadyal , Dhok Karamabad ,Dhok Matkial and Nasirabads.

Figure 3: Chart Depicating Number of Monthly Medicolegal cases

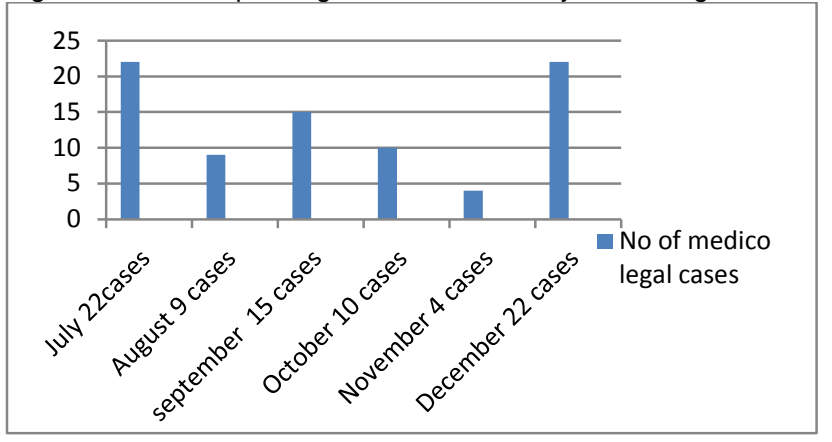

According to age groups, the frequency and percentage of injuries are shown in Table 1. The data shows that our population's 20-39-year-olds had the highest rate of gunshot injuries (72\%). Head \& Neck was the most usually impacted body region in the age range of 21-40 years, while 41-60 years was the least affected. The Chest, Abdomen, and Pelvis regions of the trunk are likewise most typically impacted between the ages of 21 and 40 , and are least affected beyond the age of 60 . It is the least impacted area of the body. The Multiple category is used when more than one region is affected, such as the extremities and trunk. 21-40-year-olds are most afflicted, whereas 0-20-year-olds are the least affected.

In all incidents, only one victim was shot using a smooth bore weapon (1.3\%), while the remainder were struck by rifled weapons (98.7 percent).

Table 1: Agee-Wise Distribution of victim of Non-Fatal Firearm Injuries in District Rawalpindi JUL-DEC 2020

\begin{tabular}{|l|l|l|l|l|}
\hline Age group & $\begin{array}{l}\text { Under } 19 \\
\text { years }\end{array}$ & $\begin{array}{l}20-39 \\
\text { years }\end{array}$ & $\begin{array}{l}40-59 \\
\text { years }\end{array}$ & $\begin{array}{l}60 \text { and } \\
\text { above }\end{array}$ \\
\hline Frequency & 13 & 59 & 5 & 5 \\
\hline Percentage & $16 \%$ & $72 \%$ & $6 \%$ & $6 \%$ \\
\hline
\end{tabular}

\section{DISCUSSION}

The results of our study showed that young men were at a higher risk for firearm-related injuries than young females were. Body regions afflicted included the lower limbs, 
abdomen and pelvis, and the lower back. On admission at the hospital, the majority of patients had a GCS of less than 13, and the mean ISS was 6 . Hospitalization lasted, on average, seven days. Shotguns and Kalashnikov rifles with high velocity were utilized to inflict firearm injuries. (6) (16) According to Pakistani studies, the male gender is a highrisk category, and the 21-40 year old age range is the most afflicted. In Pakistan, however, women have also been reported to have been injured by firearms. Due to their gender roles, men are more exposed to the outside environment than women, which could explain the increased frequency of firearm-related injuries among males. Most injuries occurred in the lower limb, abdomen, and pelvis. In other research, the head and chest were the most impacted bodily parts (19) As a result of the GCS score, the ISS score, and the length of hospital stay, the injuries were judged to be mild. However, caution should be exercised when drawing inferences from these findings, as the severity of firearm-related wounds relies largely on the distance from the shooter and whether a plastic pellet has been embedded in the wound (12) Since the study was conducted in only one location it is difficult to extrapolate the data and compute firearm injury rates in our population. (12) When estimating intentional injuries in Rawalpindi, police or emergency department data alone are insufficient. We nonetheless give significant information on firearmrelated injuries in a low-income environment, despite these constraints." Also included are some prevention methods for various types of injuries.

\section{CONCLUSION}

According to the report, young males should be targeted for lifestyle changes, such as instruction to stop from anger or conflicts (typically over small things), and to avoid the easy access to firearms as a weapon to settle disagreements. Injuries from firearms remain a public health concern. The necessity for a district-based, nationwide reporting system for fatal and nonfatal firearm-related injuries is critical. In Pakistan, these data could be used in the design, implementation, and assessment of preventative programs.

\section{REFERENCES:}

1. The Quaran, download the Quran here in full length pdf [Internet]. [cited 2021 Jul 31]. Available from: https://holybooks.com/download-the-quran-in-english/

2. AhleSunnat - All Download PDF [Internet]. [cited 2021 Jul 31]. Available from: https://www.ahlesunnatpak.com/research-paper/downloadpdf/others

3. Hootman JM, Annest JL, Mercy JA, Ryan GW, Hargarten $\mathrm{SW}$. National estimates of non-fatal firearm related injuries other than gunshot wounds. Inj Prev [Internet]. 2000 Dec 1 [cited 2021 Jul 31];6(4):268-74. Available from: https://injuryprevention.bmj.com/content/6/4/268

4. Alonge O, Agrawal P, Talab A, Rahman QS, Rahman AF, Arifeen $S \mathrm{El}$, et al. Fatal and non-fatal injury outcomes: results from a purposively sampled census of seven rural subdistricts in Bangladesh. Lancet Glob Heal. 2017 Aug 1;5(8):e818-27.

5. All Reports and Publications | Pakistan Bureau of Statistics [Internet]. [cited 2021 Jul 31]. Available from: https://www.pbs.gov.pk/content/all-reports-and-publications

6. Nasrullah M, Razzak JA. Firearm Injuries Presenting to a Tertiary Care Hospital of Karachi, Pakistan. J Inj Violence
Res [Internet]. 2009 Jul 1 [cited 2021 Jul 30];1(1):27. Available from: /pmc/articles/PMC3134905/

7. Ameer $\mathrm{Y}$, Ambreen S, Amin Mengal F, Abbasi H, Ali Khan A, Sabeeh $S$, et al. Spectrum of Firearm injury cases brought to Medicolegal Department in Sandeman (Prov) Hospital Quetta during 2000. 8(4).

8. DISTRIBUTION OF FIREARM INJURIES PRESENTED TO SURGICAL DEPARTMENT OF DHQ TEACHING HOSPITAL BANNU, PAKISTAN. - Free Online Library [Internet]. [cited 2021 Jul 31]. Available from: https://www.thefreelibrary.com/DISTRIBUTION+OF+FIREA RM+INJURIES+PRESENTED+TO+SURGICAL+DEPARTM ENT+OF...-a0523449365

9. Hyder AA, Razzak JA. The challenges of injuries and trauma in Pakistan: An opportunity for concerted action. Public Health. 2013 Aug;127(8):699-703.

10. D L, A L. Suicide rates in Canada before and after tightening firearm control laws. Psychol Rep [Internet]. 1993 [cited 2021 Jul 30];72(3 Pt 1):787-90. Available from: https://pubmed.ncbi.nlm.nih.gov/8332684/

11. Santaella-Tenorio J, Cerdá M, Villaveces A, Galea S. What Do We Know about the Association between Firearm Legislation and Firearm-Related Injuries? Epidemiol Rev. 2016 Jan 1;38(1):140-57.

12. $A L B, D M F, L J H$. Firearms legislation and reductions in firearm-related suicide deaths in New Zealand. Aust N Z J Psychiatry [Internet]. 2006 Mar [cited 2021 Jul 30];40(3):253-9. Available from: https://pubmed.ncbi.nlm.nih.gov/16476153/

13. Abdul Wasay Khan CFM. An Autopsy Based Study of Pattern of Firearm Injuries in Karachi, Pakistan. Emerg Med Open Access. 2013;03(06).

14. (PDF) Pattern of firearm injury and outcome [Internet]. [cited 2021 Jul 31]. Available from: https://www.researchgate.net/publication/289781036_Patter n_of_firearm_injury_and_outcome

15. Sobrino J, Shafi $\bar{S}$. Timing and Causes of Death After Injuries. Baylor Univ Med Cent Proc. 2013 Apr;26(2):120-3.

16. Chotani H, Razzak J, Prevention SL-I, 2002 undefined. Patterns of violence in Karachi, Pakistan. injuryprevention.bmj.com [Internet]. [cited 2021 Jul 30]; Available https://injuryprevention.bmj.com/content/8/1/57.short

17. Shah MM, Ali U, -Uz-Zaman F, Khan D, Seema N, Jan A, et al. MORBIDITY \& MORTALITY OF FIREARM INJURY IN PESHAWAR REGION. J Ayub Med Coll Abbottabad [Internet]. 2008 [cited 2021 Jul 30];20(2). Available from: http://www.ayubmed.edu.pk/JAMC/Past/20-2/Mujahid.pdf

18. Richardson J, ... DD-J of T and, 1996 undefined. After the shooting stops: follow-up on victims of an assault rifle attack. journals.Iww.com [Internet]. [cited 2021 Jul 30]; Available from:

https://journals.Iww.com/jtrauma/Fulltext/1996/11000/Depen dency_After_Hip_Fracture_in_Geriatric.4.aspx?casa_token= QA8D5LZA0HwAAAAA:NB4T6y0O-

B9K0WLM1FW6nt9uPUbNu1IYkmUlh-

ffVOFhHqoGEPMbBKOrJRzo4NIUx8VCKNVtEYRMLLvlg5A xIVs

19. Nadeem S, Naheed K, ljaz R, Ambreen S, Aslam M. Small arms, major transgressions: Exploring homicidal deaths by firearms in city of Faisalabad, Pakistan. Prof Med J. 2020 Oct 10;27(10):2170-5.

20. Javeed F, Abbas A, Rehman L, Rizvi SRK, Afzal A, Aziz HF. Outcome of cranial firearm injuries in civilian population based on a novel classification system. Surg Neurol Int. 2020 Jun 27;11.

21. JPMA - Journal Of Pakistan Medical Association [Internet]. [cited 2021 Jul 31]. Available from: https://jpma.org.pk/article-details/3928 